\title{
Phase control of ferromagnetic copper(II) carbonate coordination polymers through reagent concentration
}

\author{
David Z. T. Mulrooney, ${ }^{[a]}$ John E. Clements, ${ }^{[b]}$ Daniel J. Ericsson, ${ }^{[c]}$ Jason R. Price, ${ }^{[c]}$ Irina A. Kühne, ${ }^{[a]}$ \\ Simon J. Coles, ${ }^{[\mathrm{d}]}$ Cameron J. Kepert ${ }^{[\mathrm{b}]}$ and Tony D. Keene ${ }^{\star[a]}$
}

\begin{abstract}
A significant degree of control over the dimensionality and magnetic connectivity of $\mathrm{Cu}$ (II) carbonate coordination polymers is achieved through varying the concentration of ammonia in the reactant solution. Higher concentration leads to a two-dimensional ferromagnetic $\left[\mathrm{Cu}_{3}\left(2,4^{\prime}-\text { bipy }\right)_{6}\left(\mathrm{CO}_{3}\right)_{2}\right]_{n}^{2 n+}$ kagome structure while lower concentration develops a ferromagnetic $\left[\mathrm{Cu}\left(2,4^{\prime}\right.\right.$ bipy $\left.)_{2}\left(\mathrm{H}_{2} \mathrm{O}\right)_{2}\right]\left[\mathrm{Cu}\left(2,4^{\prime} \text { '-bipy }\right)_{2}\left(\mathrm{CO}_{3}\right)_{2}\right]$ chain (where 2,4'-bipy $=2,4^{\prime}$ bipyridine). The carbonate anion in the structures arises from the fixation of atmospheric $\mathrm{CO}_{2}$ by the basic ammonia solution. Modelling the magnetic susceptibility of $\mathbf{1}$ and 2 reveals ferromagnetic interactions with $J / k_{B}=+28.1 \mathrm{~K}$ for 1 and $+13.99 \mathrm{~K}$ for 2 . $(H=-J)$. The use of a monodentate polypyridine ligand results in the suppression of the superexchange pathway between layers in 1, removing the metamagnetic behaviour seen in related compounds where a ditopic ligand presents the ability for the layer to couple antiferromagnetically. Attempts to substitute 2,4'-bipy for 4-(N,N-dimethylamino)pyridine (4dmap) result in a discrete species $\left[\mathrm{Cu}(4-\mathrm{ampy})_{4}\right]\left(\mathrm{ClO}_{4}\right)_{2}(3)$.
\end{abstract}

\section{Introduction}

Coordination polymers in the form of metal-organic frameworks (MOFs) are at the leading edge of carbon capture and sequestration technology development, presenting significant potential for the separation, capture and utilisation of carbon dioxide through use of their porosity and selectivity for guest species. ${ }^{[1-3]} \mathrm{A}$ further inorganic route for the sequestration of $\mathrm{CO}_{2}$ is through complexation using strong bases to form carbonate, which can be locked into insoluble materials ${ }^{[4]}$ or utilised as a chemical feedstock through inorganic routes such as the Solvay process $^{[4]}$ or in organic synthesis. ${ }^{[5]}$

Carbonate is of interest in inorganic research as it can carry a magnetic interaction through superexchange, making it a desirable building block in extended materials and its multidentate coordination modes allow for a wide range of possible structure types.

[a] School of Chemistry, University College Dublin, Belfield, Dublin 4, Ireland

E-mail: tony.keene@ucd.ie

https://people.ucd.ie/tony.keene

[b] School of Chemistry, The University of Sydney, NSW 2008, Australia

[c] ANSTO, Australian Synchrotron, 800 Blackburn Road, Clayton, Vic 3168, Australia

[d] National Crystallography Service, University of Southampton, University Road, Highfield, Southampton, SO17 1BJ, UK.

Supporting information for this article is given via a link at the end of the document.
Our previous work ${ }^{[6]}$ has explored the ability of strongly basic ammonia solutions containing copper to complex atmospheric $\mathrm{CO}_{2}$ in order to form magnetically-active and multifunctional coordination polymers and MOFs. As well as the kagome lattices formed in the previous example and by others, ${ }^{[7,8]}$ a common motif of copper and carbonate in the presence of an amine ligand is chain formation. ${ }^{[9-17]}$ These lattices and chains predominantly display ferromagnetic interactions between $\mathrm{Cu}$ (II) centres. In this work, we have used aqueous ammonia as a multipurpose solvent - not only stabilising solutions of the reagents (which precipitate out in water) and acting as a source of hydroxide for carbonate formation, but also as a means of controlling structure and dimensionality in coordination polymers through concentration. Further control over dimensionality of coordination polymers was investigated through the use of a non-chelating and non-bridging bipyridine, 2,4'-bipy (Scheme 1), resulting in two new coordination polymers, $\left[\mathrm{Cu}_{3}\left(2,4^{\prime}-\text {-bipy }\right)_{6}\left(\mathrm{CO}_{3}\right)_{2}\right]\left(\mathrm{ClO}_{4}\right)_{2} \cdot 3 \mathrm{H}_{2} \mathrm{O}$ (1) and $\left[\mathrm{Cu}\left(2,4^{\prime}-\text {-bipy }\right)_{2}\left(\mathrm{H}_{2} \mathrm{O}\right)_{2}\right]\left[\mathrm{Cu}\left(2,4^{\prime} \text {-bipy }\right)_{2}\left(\mathrm{CO}_{3}\right)_{2}\right] \cdot 2 \mathrm{H}_{2} \mathrm{O}$ (2) while 4-dimethylaminopyridine (4-dmap) leads to $\left[\mathrm{Cu}\left(\mathrm{ClO}_{4}\right)_{2}(4-\right.$ dmap) 4 ] (3).



2,4-bipy

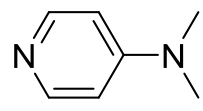

4-dmap
Scheme 1. Ligands used in this work: 2,4'-bipy = 2,4'-bipyridine; 4-dmap $=\mathrm{N}, \mathrm{N}$-dimethyl-4-aminopyridine.

\section{Results and Discussion}

The structure of $\mathbf{1}$ (formed from $>18 \% \mathrm{NH}_{3(\mathrm{aq})}$, Figure 1a) consists of two copper(II) ions, one carbonate anion, three disordered 2,4' bipy molecules, five disordered perchlorate anions and six disordered water molecules (Figure S1, ESI). Cu1 lies on an inversion centre at the centre of the cell and is chelated by the carbonate anion ( $\mathrm{Cu}-\mathrm{O}$ distances of 1.9647(19) $\AA$ and 2.5897(19) $\AA$ ) and by a disordered 2,4'-bipy ( $\mathrm{Cu}-\mathrm{N}=2.052(6)$ and $1.987(6)$ $\AA$ ) to give a trans $-\mathrm{N}_{2} \mathrm{O}_{2}$ coordination sphere in the $d_{x^{2}-y^{2}}$ orbital of the $\mathrm{Cu}(\mathrm{II})$ atom, plus two long $\mathrm{Cu}-\mathrm{O}$ bonds in the $d_{z^{2}}$. Cu2 lies on a general position with a similar trans $-\mathrm{N}_{2} \mathrm{O}_{2}+\mathrm{O}_{2}$ coordination sphere to Cu1 $(\mathrm{Cu}-\mathrm{O}=1.9531(19)$ and 2.690(2) $\AA$; average $\mathrm{Cu}-\mathrm{N}=2.005 \AA$ ). The carbonate chelates three $\mathrm{Cu}(\mathrm{II})$ centres to give three $\mathrm{Cu} \cdots \mathrm{Cu}$ distances of 4.6491(6), 4.6156(7) and 4.5310(6) $\AA$. The coordination of copper to carbonate leads to the formation of a $\left[\mathrm{Cu}_{3}\left(\mathrm{CO}_{3}\right)_{2}(2,4-\text { bipy })_{6}\right]_{n}^{2 n+}$ kagome lattice structure 
in the ab-plane (figure $1 \mathrm{~b}$, left) with 2,4'-bipy molecules standing perpendicular to this (Figure $1 \mathrm{~b}$, right). These layers then stack in the $c$-axis with an interlayer separation of 21.291(4) $\AA$ (Figure S2, $\mathrm{ESI}$ ). There are continuous voids running in the $c$-axis through the hexagonal aperture of the kagome lattices, which are filled by the heavily disordered water and perchlorate anions to charge balance the lattice. The interlayer packing consists of $\mathrm{C}-\mathrm{H} \cdots \mathrm{O}$ interactions between the non-coordinating ring of the 2,4'-bipy molecules and the perchlorate anions (Table S5, ESI).

\begin{tabular}{|c|c|c|c|}
\hline Compound & 1 & 2 & 3 \\
\hline \multirow[t]{2}{*}{ Formula } & $\mathrm{C}_{62} \mathrm{H}_{54} \mathrm{Cl}_{2} \mathrm{Cu}_{3} \mathrm{~N}_{12} \mathrm{O}_{1}$ & $\mathrm{C}_{21} \mathrm{H}_{20} \mathrm{CuN}_{4} \mathrm{O}$ & $\mathrm{C}_{28} \mathrm{H}_{40} \mathrm{Cl}_{2} \mathrm{CuN}_{8} \mathrm{O}$ \\
\hline & 7 & 5 & 8 \\
\hline $\begin{array}{l}\text { Formula } \\
\text { weight }\end{array}$ & 1501.01 & 471.95 & 751.12 \\
\hline Crystal system & Trigonal & Monoclinic & Triclinic \\
\hline Space group & $P \overline{3}$ & $C 2 / \mathrm{c}$ & $P \overline{1}$ \\
\hline$a / \AA$ & $15.929(2)$ & $11.760(2)$ & $10.9097(2)$ \\
\hline$b / \AA$ & $15.929(2)$ & $23.703(5)$ & $16.5178(3)$ \\
\hline$c / \AA$ & $21.291(4)$ & $13.800(3)$ & $20.0666(4)$ \\
\hline$\alpha 1^{\circ}$ & 90 & 90 & $97.4196(17)$ \\
\hline$\beta /{ }^{\circ}$ & 90 & $98.06(3)$ & $103.3456(16)$ \\
\hline$y /{ }^{\circ}$ & 120 & 90 & $103.2520(16)$ \\
\hline$V / \AA^{3}$ & $4678.5(16)$ & $3808.7(14)$ & $3360.89(12)$ \\
\hline $\begin{array}{l}\text { Data/restraints } \\
\text { / parameters }\end{array}$ & $9403 / 214 / 428$ & $6086 / 0 / 287$ & $15400 / 0 / 875$ \\
\hline $\begin{array}{l}\text { Goodness-of- } \\
\text { fit on } F^{2}\end{array}$ & 1.077 & 1.066 & 1.039 \\
\hline $\begin{array}{l}\text { Final } R \\
\text { indexes } \\
{[I \geq 2 \sigma(I)]}\end{array}$ & $\begin{array}{l}R_{1}=0.0780 \\
w R_{2}=0.2312\end{array}$ & $\begin{array}{l}R_{1}=0.0376 \\
w R_{2}=0.1147\end{array}$ & $\begin{array}{l}R_{1}=0.0381 \\
w R_{2}=0.0862\end{array}$ \\
\hline CCDC no. & 1859425 & 1859426 & 1859427 \\
\hline
\end{tabular}

a)

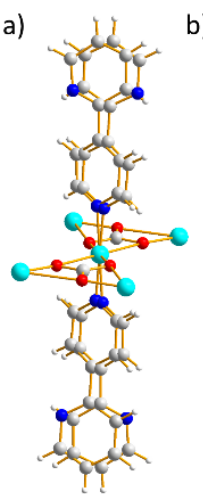

b)

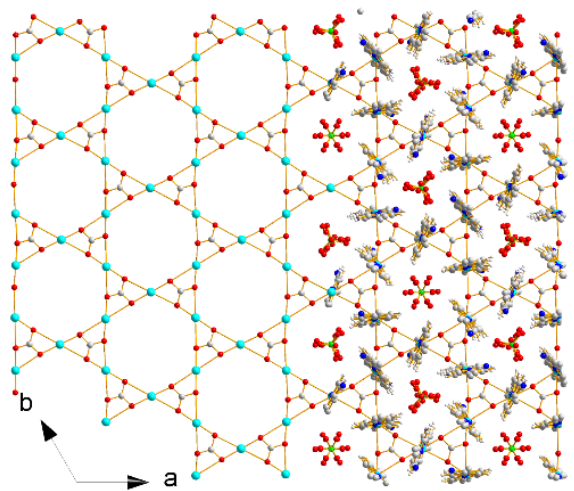

Figure 1. a) Local coordination environment of the $\mathrm{Cu}$ (II) centre in $\mathbf{1}$ showing the basis of the kagome lattice; b) view down the $c$-axis of the $\left[\mathrm{Cu}_{3}\left(\mathrm{CO}_{3}\right)_{2}\right]^{2+}$ kagome lattice (left hand side) and full structure of the layer (right hand side).

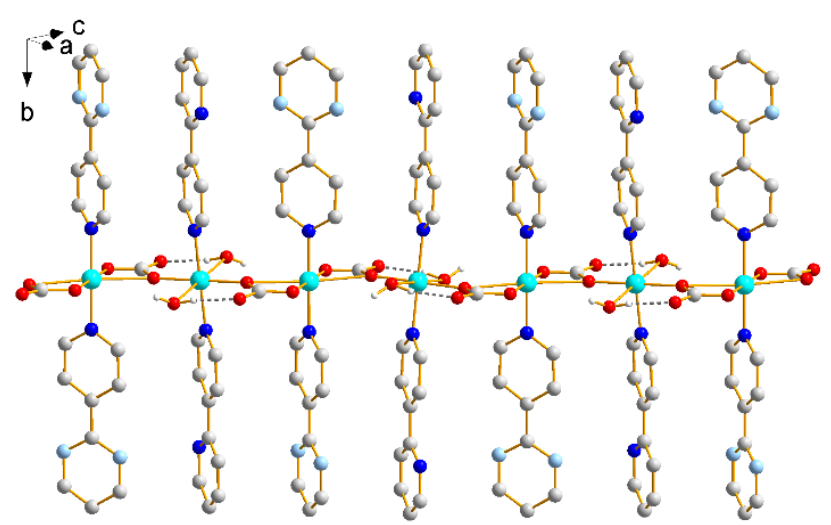

Figure 2. View of the $\left[\mathrm{Cu}(\mathrm{II})\left(2,4^{\prime}-\text { bipy }\right)_{2}\left(\mathrm{H}_{2} \mathrm{O}\right)_{2}\right]\left[\mathrm{Cu}(\mathrm{II})\left(2,4^{\prime}-\text {-bipy }\right)_{2}\left(\mathrm{CO}_{3}\right)_{2}\right]$ chain in 2 looking just off of the $10 \overline{1}$ axis. Mixed $\mathrm{C} / \mathrm{N}$ sites represented in pale blue.

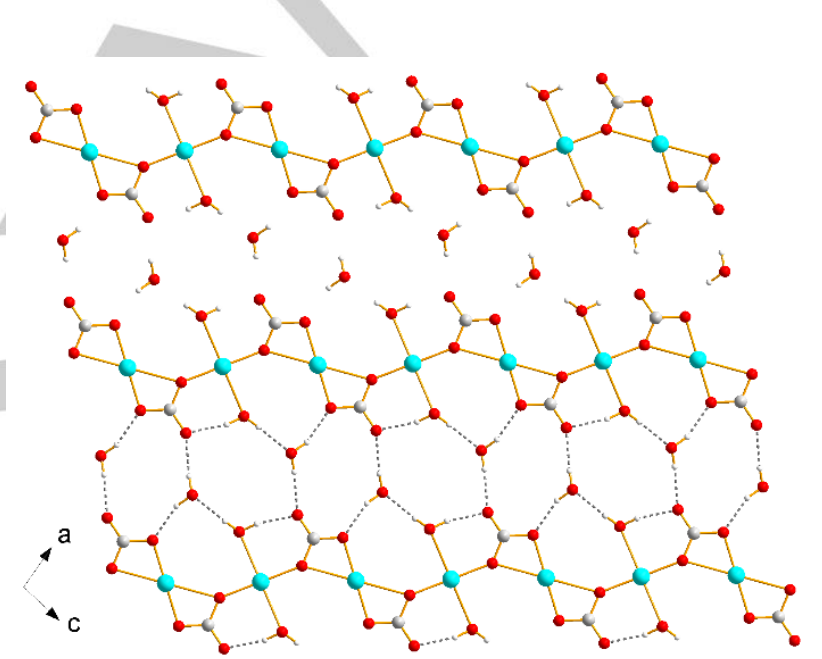

Figure 3. View of the intra- (upper) and inter-chain (lower) hydrogen bonding interactions in $\mathbf{2}$, looking down the $b$-axis.

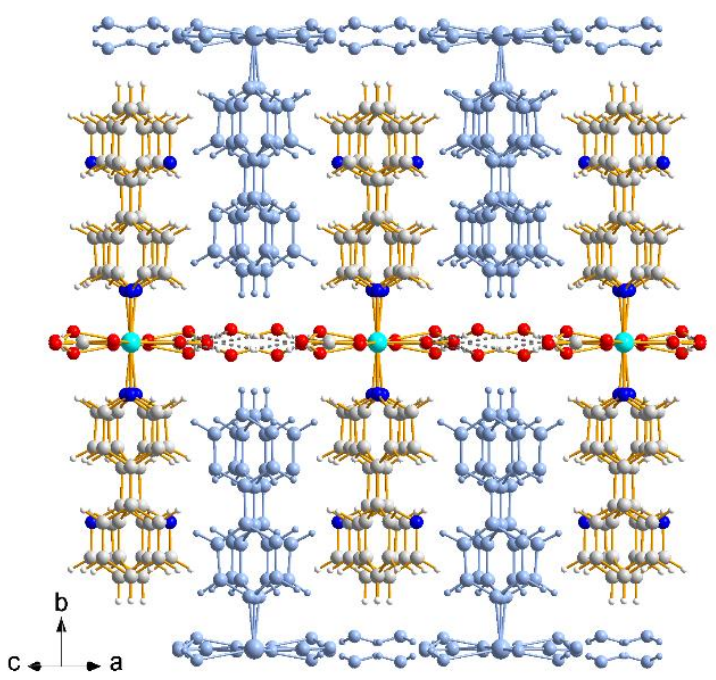

Figure 4. Packing of hydrogen-bonded layers of chains in $\mathbf{2}$, looking down the 101 axis. 


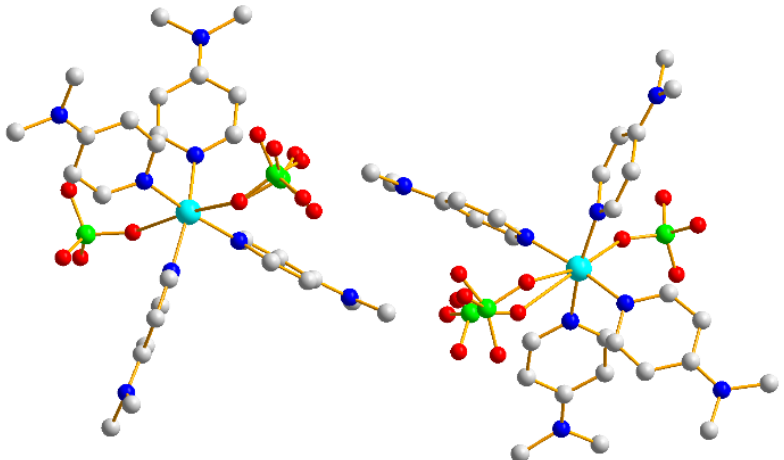

Figure 5. Structure of compound $\mathbf{3}$ showing both ordered and disordered coordinated perchlorate moieties.

The asymmetric unit of 2 (formed from $<18 \% \mathrm{NH}_{3(\mathrm{aq})}$, Figure S3, ESI) consists of two copper(II) ions, one carbonate anion, three 2,4'-bipy ligands and two water molecules. Cu1 lies on a two-fold rotation axis and is chelated by the carbonate with Cu1-O distances of 1.9784(13) $\AA$ for O4 and 2.4678(12) $\AA$ for O5 and is trans-coordinated by two 2,4 '-bipy ligands with $\mathrm{Cu} 1-\mathrm{N}$ distances of $1.9908(18) \AA$ for $\mathrm{N} 11$ and 2.0036(18) $\AA$ for N22. This gives rise to a trans- $\left[\mathrm{Cu}\left(2,4^{\prime}-\text { bipy }\right)_{2}\left(\mathrm{CO}_{3}\right)_{2}\right]^{2-}$ unit where the short $\mathrm{Cu}-\mathrm{O}$ and $\mathrm{Cu}-\mathrm{N}$ bonds denote the $d_{x^{2}-y^{2}}$ orbital. The long $\mathrm{Cu}-\mathrm{O}$ bonds define the $d_{z^{2}}$ orbital and the orientation of this is $32.00(2)^{\circ}$ from perpendicular to the plane of the $d_{x^{2}-y^{2}}$ orbital. Cu2 lies on an inversion centre and is coordinated by a 2,4'-bipy molecule with a Cu2-N31 distance of 2.0413(13) $\AA$, an oxygen atom of the carbonate from the $\left[\mathrm{Cu}\left(2,4^{\prime}-\mathrm{bipy}\right)_{2}\left(\mathrm{CO}_{3}\right)_{2}\right]^{2-}$ unit $(\mathrm{Cu} 2-\mathrm{O} 5=$ $1.9605(11) \AA$ ) and a water molecule (Cu2-O8 $=2.4427(12) \AA$ ). Thus, the carbonate and the 2,4'-bipy around Cu2 denote the $d_{x^{2}-y^{2}}$ orbital and the trans water molecules define the $d_{z^{2}}$. The carbonate anion bridges the two copper atoms (Cu1 $\cdots \mathrm{Cu} 2=$ 4.2074(14) A, Cu1-O5-Cu2 = 143.40(5) $\left.{ }^{\circ}\right)$ which forms a $\left[\mathrm{Cu}\left(2,4^{\prime}\right.\right.$ bipy $\left.)_{2}\left(\mathrm{H}_{2} \mathrm{O}\right)_{2}\right]\left[\mathrm{Cu}\left(2,4^{\prime} \text {-bipy }\right)_{2}\left(\mathrm{CO}_{3}\right)\right]$ chain (Figure 2$)$ in the 101 axis, additionally stabilised by intrachain hydrogen bonding between the water molecules and carbonates (Figure 3 and Table S6, ESI). An additional water of crystallisation hydrogen bonds between the carbonate and water moieties of neighbouring chains to produce a hydrogen-bonded network in the ac-plane (Figure 3 lower). The 2,4 '-bipy molecules are held perpendicular to this plane and interdigitate with neighbouring planes in the $b$-axis to form the three-dimensional structure of compound 2 (Figure 4).

The structure of 3 (Figure 5) consists of two copper(II) ions, each coordinated by four 4-dmap molecules and two perchlorates. The 4-dmap molecules coordinate in a square plane in the $d_{x^{2}-y^{2}}$ orbital, as denoted by the short $\mathrm{Cu}-\mathrm{N}$ bond lengths (average 2.0071(16) $\AA$ ) while the perchlorate anions coordinate in the $d_{z^{2}}$ orbital with $\mathrm{Cu}-\mathrm{O}$ distances of 2.642(4) $\AA$, giving a trans $-\mathrm{N}_{4} \mathrm{O}_{2}$ coordination sphere around the $\mathrm{Cu}(\mathrm{II})$ ions. Two of the $\left[\mathrm{Cu}(\mathrm{II})\left(\mathrm{ClO}_{4}\right)_{2}(4-\mathrm{dmap})_{4}\right]$ complexes are found in the asymmetric unit. On each complex, one perchlorate is ordered and one disordered (76:24 for $\mathrm{Cl} 2 / \mathrm{Cl} 3$ and $92: 8$ for $\mathrm{Cl} 5 / \mathrm{Cl} 6)$. The units pack through $\mathrm{C}-\mathrm{H} \cdots \mathrm{O}$ interactions (Figure S5, ESI) between 4dmap and the perchlorate anions, isostructural to $\left[\mathrm{Cu}(\mathrm{II})(\mathrm{dmap})_{4}\left(\mathrm{BF}_{4}\right)_{2}\right]^{[18]}$

\section{Discussion}

The crystallisation of compounds $\mathbf{1}$ and $\mathbf{2}$ is dependent on the concentration of ammonia in the reaction solution. Starting with $25 \% \mathrm{NH}_{3}$, dark blue hexagonal crystals of $\mathbf{1}$ are formed, but as the reaction proceeds and ammonia is lost to evaporation, light blue needles of 2 form. Further reaction time sees the crystals of $\mathbf{1}$ disappear, indicating that $\mathbf{1}$ is a kinetic product while $\mathbf{2}$ is the thermodynamic product. At lower starting concentrations of ammonia, only compound $\mathbf{2}$ is formed. It is unusual in coordination polymer chemistry to precipitate a phase and then have it redissolve to produce a new phase as a result of decreasing reagent concentration, as seen in the case of $\mathbf{1}$ and $\mathbf{2}$.

The ability to form both a kagome and a chain structure with the same ligand has been seen previously with 4-ampy (where 4ampy $=4$-aminopyridine). The difference in this case is that the two compounds require different reaction conditions and reagents. In the synthesis of the kagome $\{[\mathrm{Cu}(4-$ ampy $\left.\left.)_{2}\right]_{3}\left(\mathrm{CO}_{3}\right)_{2}\left(\mathrm{ClO}_{4}\right)_{2} \cdot \mathrm{CH}_{3} \mathrm{OH}\right\}_{n},{ }^{[8]} \mathrm{NaOH}$ is the source of hydroxide for carbonate formation while in the chain compound $\left[\mathrm{Cu}(4 \text {-ampy })_{2}\left(\mathrm{CO}_{3}\right)\right] \cdot \mathrm{H}_{2} \mathrm{O},{ }^{[10]}$ ammonia solution is used. Attempts by our group to produce the 4-ampy kagome using ammonia solution always lead to the chain structure.

The kagome lattice found in $\mathbf{1}$ is particularly sought-after in molecular magnetism due to the potential for frustrated ground states when antiferromagnetically-coupled, revealing new insights into the physics of geometrically frustrated systems. ${ }^{[19,20]}$ While the type of structure seen in $\mathbf{1}$ contains the kagome lattice, the interactions between $\mathrm{Cu}$ (II) centres chelated and bridged by carbonate are ferromagnetic, relieving any frustration. Nonetheless, the structural control and predictability of the formation of kagomes by $\mathrm{CO}_{3}{ }^{2-}$ remain of significant interest in the design and synthesis of model systems for the investigation of molecular magnetism.

There are comparatively few $\mathrm{Cu}$ (II) carbonate chain compounds reported where a magnetic interaction could be carried along $\mathrm{Cu}-\mathrm{O}-\mathrm{Cu}$ bonds through the $d_{x^{2}-y^{2}}$ orbital, which represent three specific structure types, plus one variant (Figure 6). In each type, the short $\mathrm{Cu}-\mathrm{O}$ bonds to carbonate groups are trans. Types ${ }^{\left[{ }^{[9]}\right.}$ and $\mathrm{II}^{[11]}$ have simple repeating $\left[\mathrm{Cu}(\mathrm{II})\left(\mathrm{CO}_{3}\right)\right]$ units while type III contains alternating $\left[\mathrm{Cu}\left(\mathrm{H}_{2} \mathrm{O}\right)_{2}\right]^{2+}$ and $\left[\mathrm{Cu}\left(\mathrm{CO}_{3}\right)_{2}\right]^{2-}$ units. ${ }^{[12,13]}$ Compound 2 and $\left[\mathrm{Cu}\left(\mathrm{H}_{2} \mathrm{O}\right)_{2}(\mathrm{py})_{2}\left[\mathrm{Cu}(\mathrm{py})_{2}\left(\mathrm{CO}_{3}\right)_{2}\right] \cdot 2 \mathrm{H}_{2} \mathrm{O}\right.$ (where py $=$ pyridine ${ }^{[12,13]}$ display the latter chain type. While each type has a different underlying motif, each displays a single bridging pathway between $\mathrm{Cu}(\mathrm{II})$ ions, greatly simplifying the magnetic analysis of each compound. An exception is $[\mathrm{Cu}(4-$ ampy $\left.)_{2}\left(\mathrm{CO}_{3}\right)\right] \cdot \mathrm{H}_{2} \mathrm{O}$, ${ }^{[10]}$ which is a subtype of the type I chain with lower crystallographic symmetry, resulting in four independent copper atoms and displays a rotational distortion to the last carbonate bridge in the chain subunit. Other copper carbonate chains exist where the magnetic interaction along the chain has to pass through a $d_{z^{2}}$ orbital, weakening the coupling. These resolve into two types. Type IV displays chelation by the carbonate into adjacent lobes of the $\mathrm{Cu}(\mathrm{II}) d_{x^{2}-y^{2}}$ orbital and a bridge to a further $\mathrm{Cu}$ (II) centre through the $d_{z^{2}}$ orbital to give a $\left[\mathrm{Cu}(\mathrm{II})\left(\mathrm{CO}_{3}\right)\right]$ repeat unit. ${ }^{[14-16]}$ Type $\mathrm{V}$ contains a $\left[\mathrm{Cu}_{2}\left(\mathrm{CO}_{3}\right)\right]^{2+}$ repeat unit where linkage between the units occurs through the 
$d_{z^{2}}$ orbitals, resulting in a strong dimer coupling within the unit and a weak intrachain interaction. ${ }^{17]}$

Attempts to use the strong base 4-dmap to replace 2,4'-bipy were unsuccessful, resulting in a discrete species rather than kagome or chain formation for reasons that are not entirely clear, hinting at limitations to the applicability of this synthetic route to other pyridine ligands, despite not being any bulkier along the molecular axis than 2,4'-bipy.
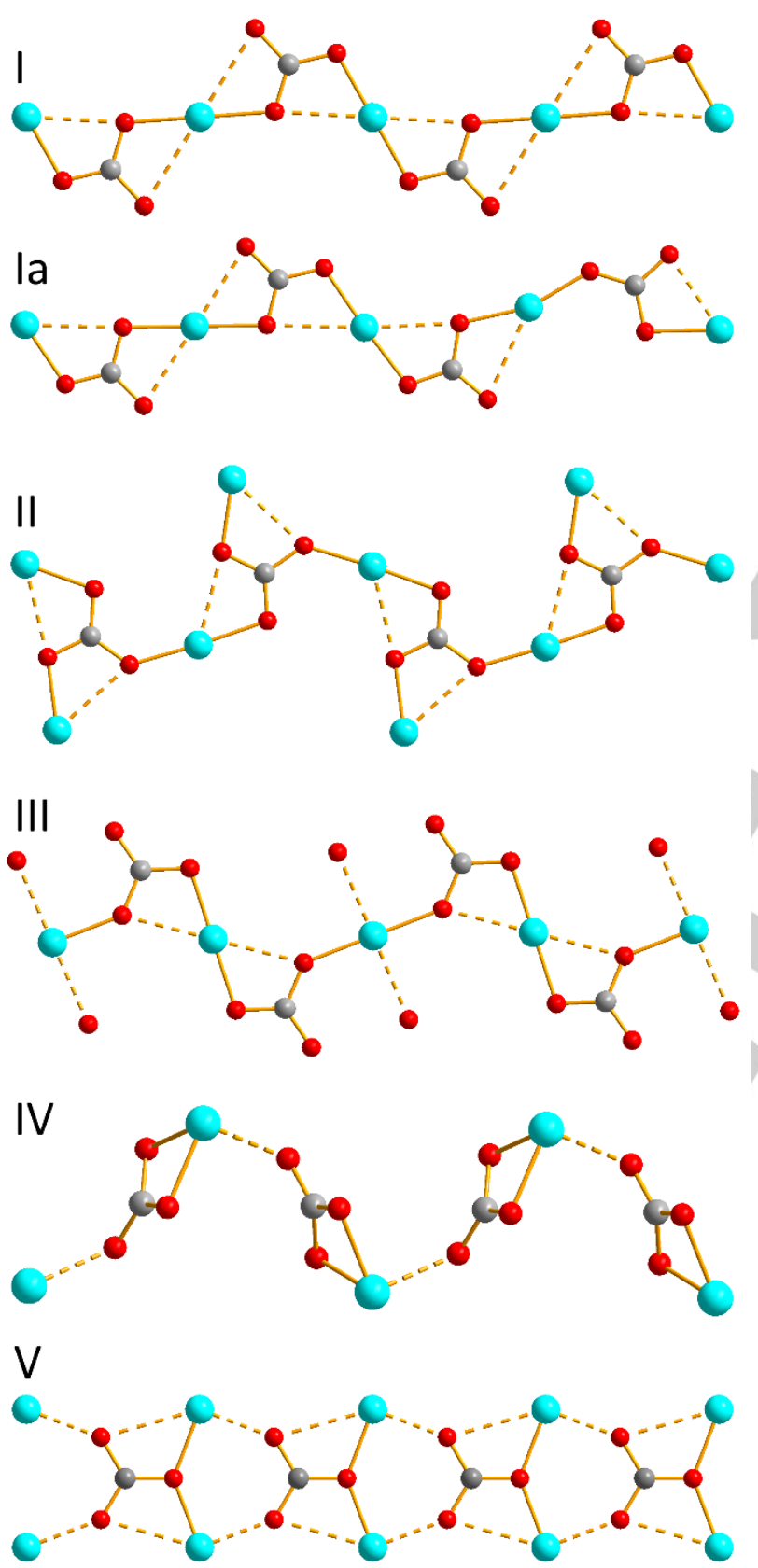

Figure 6. $\mathrm{Cu}$ (II) carbonate chain motifs from the literature. Roman numerals refer to chain type in the text. $\mathrm{Cu}(\mathrm{II})-\mathrm{O}$ interaction occurring through the $d_{x^{2}-y^{2}}$ orbital are indicated as solid bonds, those in the $d_{z^{2}}$ orbital are dashed.

\section{Magnetic properties}

The $X T(T)$ plot for compound 1 (Figure 7) shows an increasing value on cooling from $300 \mathrm{~K}$ with a sharp maximum at $6 \mathrm{~K}$, indicative of a dominant ferromagnetic interaction. The CurieWeiss plot gives $C=0.403(3) \mathrm{cm}^{3} \mathrm{Kmol}^{-1}$ and $\theta=+21.5(8) \mathrm{K}$, indicating again a ferromagnetic interaction. Previous work by our group and others ${ }^{[6,21]}$ indicates that ferromagnetic interactions occur between $\mathrm{Cu}(\mathrm{II})$ centres chelated and bridged carbonate, thus the $X T(T)$ data were modelled using a ferromagnetic $S=1 / 2$ kagome model ${ }^{[6]}$ (equations 1 and 2) to give $g=2.039(5)$ and $J / k_{B}$ $=+28.1$ (2) $\mathrm{K}$ to describe the intralayer interaction.

$H=-J \sum_{i j} S_{i} S_{j}$ eq. 1

$\chi T=\frac{N g^{2} \mu_{B}^{2}}{4 k_{B}}\left(1+\sum_{n=1}^{n=8} a_{n} K^{n}\right)$

where $K=J / k_{B} T$ and $a_{n}$ values for $n=1-8$ are given in the supporting information.

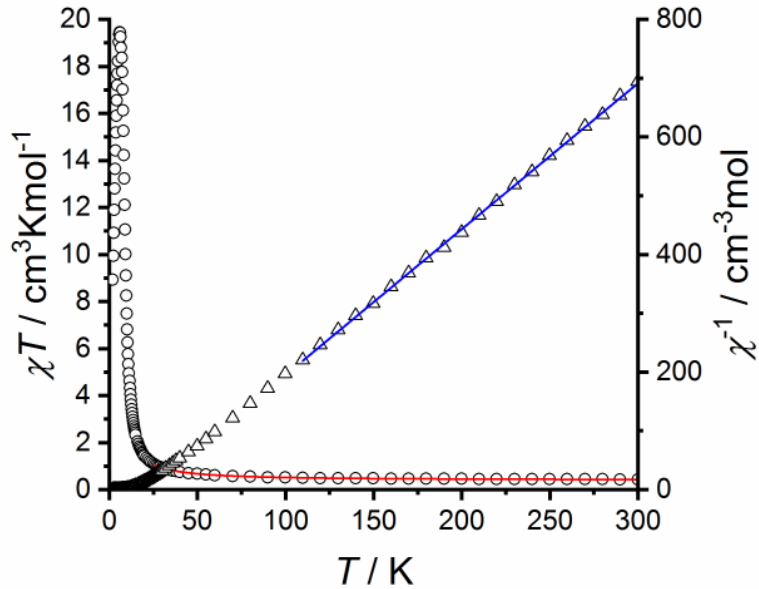

Figure 7. Left axis: $X T(T)$ plot of $1(\circ)$ with fit from $S=1 / 2$ ferromagnetic kagome model (blue line, $g=2.039(5), J / K_{B}=+28.1(2) \mathrm{K}$ ). Right axis: Inverse susceptibility plot of $1(\Delta)$ with Curie-Weiss fit (blue line, $C=0.403(3) \mathrm{cm}^{3} \mathrm{gmol}^{-1}$, $\theta=+21.5(8) \mathrm{K})$.

The coupling of $+28.1 \mathrm{~K}$ fits reasonably well with the prediction of $J$ from the model of Felix et al. ${ }^{[21]}$ This model arises from DFT calculations on the orientations of the $d_{x^{2}-y^{2}}$ orbitals of $\mathrm{Cu}$ (II) and the magnitude and sign of the interaction displays a marked dependency on the values of the $\mathrm{Cu}-\mathrm{O} \cdots \mathrm{O}$ angles across the carbonate, $\varphi_{1}$ and $\varphi_{2}$ (figure 8). For all three possible combinations in 1, the predicted coupling is $40-43 \mathrm{~K}$, however, this model is calculated for a less electronegative coordination sphere than is seen in $\mathbf{1}$, thus the coupling expected in $\mathbf{1}$ will likely be lower as less electron density is being placed onto the metal, reducing the overlap between $\mathrm{Cu}(\mathrm{II})$ centres. ${ }^{[22]}$ 


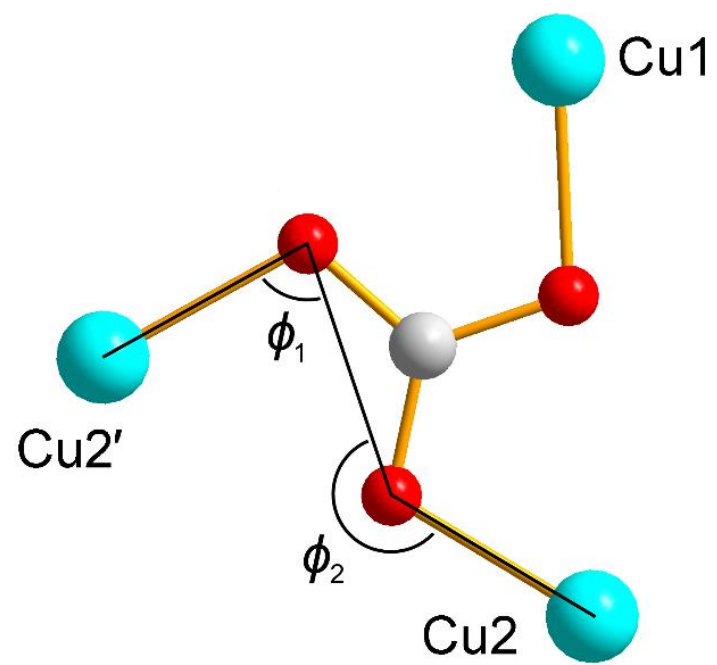

Figure 8. Angles in 1 for prediction of magnetic coupling based on $\varphi_{1}$ and $\varphi_{2}$. Cu1 $\cdots$ Cu2: $\varphi 1=79.7^{\circ}$ and $\varphi_{2}=224.2^{\circ} ;$ Cu2 $\cdots$ Cu2 ${ }^{\prime}: \varphi 1=79.4^{\circ}$ and $\varphi_{2}=220.5^{\circ}$; Cu2 $\cdots$ Cu1: $\varphi 1=79.7^{\circ}$ and $\varphi_{2}=224.2^{\circ}$.

The peak at $6 \mathrm{~K}$ in the magnetic susceptibility plot and the curvature of the field-dependent magnetisation (Figure S11, ESI) are consistent with a dominant ferromagnetic interaction, with the magnetisation rising monotonically on increasing field from $0 \mathrm{G}$ until it begins to saturate around $25 \mathrm{G}$. This strongly implies a ferromagnetic interlayer interaction, consistent with other $\left[\mathrm{Cu}(\mathrm{II})_{3}\left(\mathrm{CO}_{3}\right)_{2}\right]$ kagomes. $^{[8,23]}$

In our previous work on another $\mathrm{Cu}(\mathrm{II})$ kagome, $\left[\mathrm{Cu}_{3}(4,4\right.$ 'bipyridylacetylene $\left.)_{3}\left(\mathrm{CO}_{3}\right)_{2}\right]\left(\mathrm{ClO}_{4}\right)_{2} \cdot \mathrm{H}_{2} \mathrm{O} \quad(4),{ }^{[6]}$ a weak antiferromagnetic interlayer interaction was seen, leading to a metamagnetic transition at $\sim 100 \mathrm{G}$. The lack of a metamagnetic transition in $\mathbf{1}$ can be rationalised by inspection of the interlayer superexchange pathways in the two compounds. In 1 , there is no exchange pathway between copper atoms on neighbouring layers thus a ferromagnetic interaction is more likely in agreement with Hund's rule, whereas in $\mathbf{4}$, the $\mathrm{Cu}$ atoms in neighbouring layers are connected through the bis(4-pyridyl)acetylene ligand, thus ensuring that the $\mathrm{Cu}$ atoms are part of the same molecular orbital and thus would couple antiferromagnetically. The intralayer coupling constant in $\mathbf{1}$ is consistent with the other $\left[\mathrm{Cu}_{3}\left(\mathrm{CO}_{3}\right)_{2}\right]_{n}{ }^{2 n+}$ kagomes fitted with our model[6] and fits well with the angular dependence in $\left[\mathrm{Cu}_{3}\left(\mathrm{CO}_{3}\right)\right]$ trimers presented by Felix et al. ${ }^{[21]}$

The $X T(T)$ plot for compound 2 (Figure 9) displays an increasing value on cooling from $300 \mathrm{~K}$ without displaying a maximum indicating a dominant overall ferromagnetic interaction. Modelling the inverse susceptibility data with the Curie-Weiss equation gives $C=0.376(2) \mathrm{cm}^{3} \mathrm{Kmol}^{-1}$ and $\theta=+4.5(9) \mathrm{K}$, indicating again a ferromagnetic interaction. The $X T(T)$ data were modelled using the Baker $S=1 / 2$ chain polynomial[24] to give $g=1.982(2)$ and $J=$ $+13.99(6) \mathrm{K}$.

$\chi T=\frac{N g^{2} \mu_{B}^{2}}{4 k_{B}}\left(\frac{N}{D}\right)^{2 / 3}$ eq. 3

where $N$ and $D$ are given in the supporting information.
The coupling in 2 is consistent with that found by Julve et al. ${ }^{[10]}$ in their type la chain at $15.8 \mathrm{~K}$, which treats all four $\mathrm{Cu}-\mathrm{CO}_{3}-\mathrm{Cu}$ couplings as equivalent. None of the other type II and III chains have been investigated for their magnetic properties, limiting the ability to correlate structure and bonding to magnetic properties. The ferromagnetic couplings in $\mathbf{1}$ and $\mathbf{2}$ are likely a result of accidental orbital orthoganality, as demonstrated in other $\mathrm{Cu}(\mathrm{II})$ systems, such as dihydroxo-bridged dimers, ${ }^{[25]}$ phenol-bridged dimers ${ }^{[26,27]}$ and oxalate chains, ${ }^{[22]}$ all display a marked angular dependence on the strength and sign of the coupling.

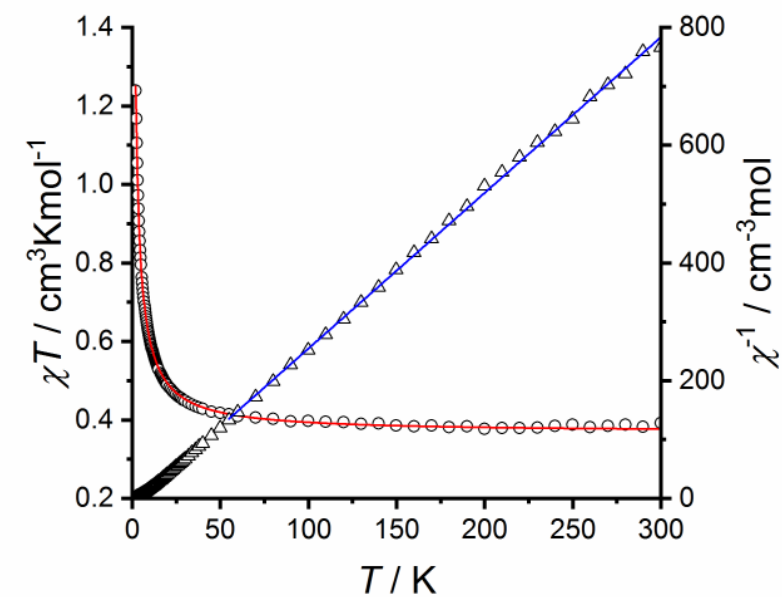

Figure 9. Left axis: $X T(T)$ plot of $2(\circ)$ with fit from $S=1 / 2$ ferromagnetic chain model (blue line, $g=1.982(2), J / K_{B}=+13.99(6) K$ ). Right axis: Inverse susceptibility plot of $2(\Delta)$ with Curie-Weiss fit (blue line, $C=0.376(2) \mathrm{cm}^{3} \mathrm{gmol}^{-1}$, $\theta=+4.5(9) \mathrm{K})$.

\section{Conclusions}

The synthesis of copper carbonate complexes with 2,4'-bipy is highly dependent on the solution concentration of ammonia, a species not included in the final structures. The structure types seen in this work (kagome and chain) are robust motifs with predictable magnetic properties, although more examples are needed of magnetic analysis of $\left[\mathrm{Cu}\left(\mathrm{CO}_{3}\right)\right]$ chains to draw firm conclusions of the structure-property relationships.

While the structural motifs seen above are transferrable across a range of pyridyl ligands, limitations can be seen in the attempt to synthesise further members of these families using 4-dmap. Further work will look at the boundaries and limitations of using pyridyl ligands in designing these types of coordination polymers.

\section{Experimental Section}

Experimental methods

Reagents were obtained from commercial suppliers and used without further purification. Single crystal X-ray diffraction data for $\mathbf{1}$ and $\mathbf{2}$ were 
collected at beamline MX-1 at the Australian Synchrotron at $100 \mathrm{~K} \cdot{ }^{[28]}$ SCXRD data for 3 were collected at $100 \mathrm{~K}$ on a Rigaku AFC12 goniometer equipped with an enhanced sensitivity (HG) Saturn 724+ detector mounted at the window of an FR-E+ Superbright Mo- $K_{\alpha}$ rotating anode generator $(\lambda$ $=0.71075 \AA$ ) with $\mathrm{HF}$ varimax optics. ${ }^{[29]}$ Unit cell parameters were refined against all data and an empirical absorption correction applied in XDS ${ }^{[30]}$ for $\mathbf{1}$ and $\mathbf{2}$ and CrysalisPro ${ }^{[31]}$ for $\mathbf{3}$. All structures were solved by direct methods using SHELXT ${ }^{[32]}$ and refined on $F^{2}$ by SHELXL-2013 ${ }^{[33]}$ in OLEX2 v1.2. ${ }^{[34]}$ All hydrogen atoms were added in calculated positions and refined in riding mode on the parent atom. Data deposited with the CSD (CSD 1859425-1859427, 1-3). Powder X-ray diffraction was carried out on 1 and 2 using a Panalytical Xpert Pro diffractometer and Cu- $K_{\alpha}$ radiation $(1.5406 \AA$ A ). Le Bail profile fits on powder X-ray data were performed in Rietica ${ }^{[35]}$ to ensure phase identity and sample purity.

Magnetic susceptibility measurements were carried out on a Quantum Design PPMS with VSM magnetometer option from 2-300 K under an applied field of $1,000 \mathrm{G}$. Diamagnetic corrections were calculated from the approximation $-0.45 \times$ formula mass $\times 10^{-6} \mathrm{~cm}^{3} \mathrm{~mol}^{-1}$

Elemental analyses were performed on an Exeter Analytical CE 440 elemental analyser.

\section{Synthesis of compounds 1-3}

Compound 1 was synthesised by dissolving $\mathrm{Cu}(\mathrm{II})\left(\mathrm{ClO}_{4}\right)_{2} \cdot 6 \mathrm{H}_{2} \mathrm{O}(93 \mathrm{mg}$, $0.25 \mathrm{mmol}$ ) and 2,4'-bipy (78 mg, $0.50 \mathrm{mmol})$ in $25 \% \mathrm{NH}_{3(\text { (aq) }}(20 \mathrm{ml})$ and the resultant blue solution left to evaporate over two days to give dark blue hexagonal plate crystals of $\mathbf{1}$ and filtered before the appearance of compound 2 ( $85 \mathrm{mg}, 65 \%$ by $\mathrm{Cu}$ ). Expected for $\mathrm{Cu}_{3} \mathrm{C}_{62} \mathrm{H}_{54} \mathrm{Cl}_{2} \mathrm{~N}_{12} \mathrm{O}_{17}(\%)$ C: $49.62, \mathrm{H}: 3.63, \mathrm{~N}: 11.20$. Found C: 50.01, H: 3.39, N:11.15.

Compound 2 was synthesised with the same method, but in $12.5 \% \mathrm{NH}_{3 \text { (aq) }}$ $(20 \mathrm{ml})$ to give light blue needles $(89 \mathrm{mg}, 75 \%$ by $\mathrm{Cu}$ ). Expected for $\mathrm{CuC}_{21} \mathrm{H}_{20} \mathrm{~N}_{4} \mathrm{O}_{5}$ (\%) C: $53.44, \mathrm{H}: 4.27, \mathrm{~N}: 11.87$. Found C: $54.28, \mathrm{H}: 4.21$, $\mathrm{N}: 12.01$.

Compound 3 was synthesised by dissolving $\mathrm{Cu}(\mathrm{II})\left(\mathrm{ClO}_{4}\right)_{2} .6 \mathrm{H}_{2} \mathrm{O}(85 \mathrm{mg}$, $0.50 \mathrm{mmol}$ ) and 4-dmap (122 mg, $1.00 \mathrm{mmol})$ in $20 \% \mathrm{NH}_{3}$ (aq) $(20 \mathrm{ml})$ and the resultant blue solution left to evaporate over 3 days to give dark blue block crystals of $\mathbf{3}$ in a mixture with insoluble powders.

\section{Supporting information}

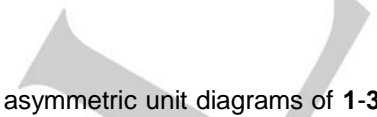

Full crystallographic refinement details; asymmetric unit diagrams of 1-3, bond length and angle tables; powder X-ray diffraction plots of $\mathbf{1}$ and 2; magnetisation plots for $\mathbf{1}$; photos of crystallisation.

\section{Acknowledgements}

I.A.K. acknowledges the Irish Research Council (IRC) for the fellowship GOIPD/2016/503. The crystallographic data for complexes 1-2 were collected on the MX beamline at the Australian Synchrotron, Victoria, Australia. JEC acknowledges the University of Sydney for a World Scholars Award.

Keywords: chain structures $\cdot$ coordination polymer $\cdot$ kagome $\bullet$ layered compounds $\cdot$ magnetic properties
[1] A. Schoedel, Z. Ji, O. M. Yaghi, Nat. Energy 2016, 1, 16034.

[2] C. A. Trickett, A. Helal, B. A. Al-Maythalony, Z. H. Yamani, K. E. Cordova, O. M. Yaghi, Nat. Rev. Mater. 2017, 2, 17045.

[3] T. P. Senftle, E. A. Carter, Acc. Chem. Res. 2017, 50, 472-475.

[4] A. A. Olajire, J. Pet. Sci. Eng. 2013, 109, 364-392.

[5] Q. Liu, L. Wu, R. Jackstell, M. Beller, Nat. Commun. 2015, 6, 1-15.

[6] T. D. Keene, M. J. Murphy, J. R. Price, N. F. Sciortino, P. D. Southon, C. J. Kepert, Dalton Trans. 2014, 43, 14766-14771.

[7] P. Kanoo, C. Madhu, G. Mostafa, T. K. Maji, A. Sundaresan, S. K. Pati, C. N. R. Rao, J. Chem. Soc. Dalt. Trans. 2009, 9226, 50625064.

[8] A. Majumder, C. R. Choudhury, S. Mitra, G. M. Rosair, M. S. El Fallah, J. Ribas, Chem. Commun. 2005, 2158.

[9] N. Masciocchi, S. Bruni, E. Cariati, S. Galli, A. Sironi, Zeitschrift für Krist. - Cryst. Mater. 2002, 217, 131-134.

[10] J. Sertucha, A. Luque, O. Castillo, P. Román, F. Lloret, M. Julve, Inorg. Chem. Commun. 1999, 2, 14-16.

[11] G. A. Bowmaker, C. Di Nicola, F. Marchetti, C. Pettinari, B. W. Skelton, N. Somers, A. H. White, Inorg. Chim. Acta 2011, 375, 3140.

[12] G. A. Bowmaker, Effendy, K. C. Lim, B. W. Skelton, D. Sukarianingsih, A. H. White, Inorg. Chim. Acta 2005, 358, 43424370.

[13] Y. Du, A. L. Thompson, N. Russell, D. O'Hare, Dalton Trans. 2010, 39, 3384-3395.

[14] M. H. Meyer, P. Singh, W. E. Hatfield, D. J. Hodgson, Acta Crystallogr. Sect. B Struct. Crystallogr. Cryst. Chem. 1972, 28, 1607-1613.

[15] M. Maciejewski, A. Baiker, H. Viebrock, U. Sazama, P. Wilde, A. Reller, Solid State Ionics 1993, 63-65, 346-350.

[16] I. Viera, L. Domínguez, J. Ellena, M. H. Torre, Zeitschrift für Naturforsch. B 2008, 63B, 543-547.

X. Zhang, S. Nishihara, Y. Nakano, K. Y. Maryunina, K. Inoue, Chem. Lett. 2014, 43, 1713-1715.

[18] C. E. Koning, G. Challa, F. B. Hulsbergen, J. Reedijk, J. Mol. Catal. 1986, 34, 355-379

[19] H. J. Liao, Z. Y. Xie, J. Chen, Z. Y. Liu, H. D. Xie, R. Z. Huang, B. Normand, T. Xiang, Phys. Rev. Lett. 2017, 118, 137202.

[20] P. Mendels, F. Bert, Comptes Rendus Phys. 2016, 17, 455-470.

[21] P. Mateus, R. Delgado, F. Lloret, J. Cano, P. Brandão, V. Félix, Chem. - A Eur. J. 2011, 17, 11193-11203.

[22] U. García-Couceiro, O. Castillo, A. Luque, J. P. García-Terán, G. Beobide, P. Román, Cryst. Growth Des. 2006, 6, 1839-1847.

[23] P. Kanoo, C. Madhu, G. Mostafa, T. K. Maji, A. Sundaresan, S. K. Pati, C. N. R. Rao, J. Chem. Soc. Dalt. Trans. 2009, 9226, 50625064

[24] G. A. Baker, G. S. Rushbrooke, H. E. Gilbert, Phys. Rev. 1964, 135, A1272-A1277.

[25] V. H. Crawford, H. W. Richardson, J. R. Wasson, D. J. Hodgson, W. E. Hatfield, Inorg. Chem. 1976, 15, 2107-2110.

[26] S. Laborda, R. Clérac, C. E. Anson, A. K. Powell, Inorg. Chem. 2004, 43, 5931-5943.

[27] I. A. Kühne, G. E. Kostakis, C. E. Anson, A. K. Powell, Chem. Commun. 2015, 51, 2702-2705. 
[28]

D. Aragão, J. Aishima, H. Cherukuvada, R. Clarken, M. Clift, N. P. Cowieson, D. J. Ericsson, C. L. Gee, S. Macedo, N. Mudie, S. Panjikar, J. R. Price, A. Riboldi-Tunnicliffe, R. Rostan, R. Willianson, T. T. Caradoc-Davies, J. Synchrotron Radiat. 2018, 25, 885-891. S. J. Coles, P. A. Gale, Chem. Sci. 2012, 3, 683-689.

[30] W. Kabsch, Acta Crystallogr. Sect. D Biol. Crystallogr. 2010, 66, 125-132.

[31] CrysAlisPro, Agilent Technologies, Version 1.171.3.

[32]
G. M. Sheldrick, Acta Crystallogr. Sect. A Found. Crystallogr. 2008, 64, 112-122. O. V. Dolomanov, L. J. Bourhis, R. J. Gildea, J. A. K. Howard, H. Puschmann, J. Appl. Crystallogr. 2009, 42, 339-341.

[35] B. Hunter, Int. Union Crystallogr. Comm. Powder Diffr. Newsl. No. 20. 1998. 8. 


\section{Entry for the Table of Contents}

\section{FULL PAPER}

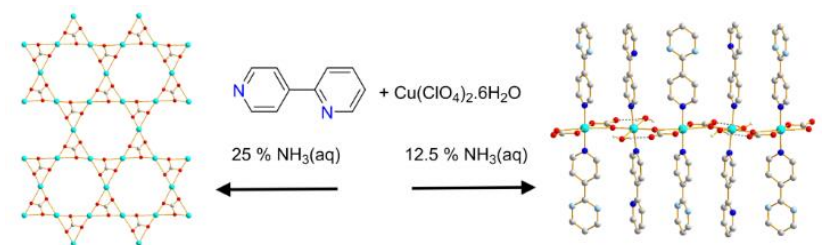

Initial ammonia concentration dictates the dimensionality of structure in a pair of ferromagnetic $\mathrm{Cu}(\mathrm{II})$ carbonate materials, giving $\left[\mathrm{Cu}_{3}\left(\mathrm{CO}_{3}\right)_{2}\right]_{n}{ }^{2 n+}$ kagome layers at higher values and $\left[\mathrm{Cu}\left(\mathrm{CO}_{3}\right)\right]_{n}$ chains as concentration decreases.

\section{Ferromagnetic carbonates}

David Z. T. Mulrooney, John E. Clements, Daniel Ericsson, Jason $R$. Price, Irina A. Kühne, Simon J. Coles, Cameron J. Kepert and Tony D. Keene*

Page No. - Page No.

Phase control of ferromagnetic copper(II) carbonate coordination polymers through reagent concentration 